\title{
Jorge de Lima no contexto da poesia negra americana ${ }^{1}$ VAGNER CAMILO
}

\author{
"Era a negra Fulô que nos chamava \\ de seu negro vergel $[\ldots]$ \\ canções de lavadeira ao pé da fonte, \\ era a fonte em si mesma, eram nostálgicas \\ emanações de infância e de futuro, \\ era um ai português desfeito em cana."
}

(Carlos Drummond de Andrade “Conhecimento de Jorge de Lima”)

$P$ OEMAS negros sai em 1947, reunindo textos já publicados e outros inéditos, datados de $1927^{2}$ até cerca de 1940. "Pode-se pensar", com Alexandre Eulálio (1992, p.481),

que a edição promovida pela Revista Acadêmica de Murilo Miranda tenha sido inspirada pelo aparecimento em 1946, em Buenos Aires, do Mapa de la Poesía Negra Americana, compilado, prefaciado e anotado pelo poeta cubano Emilio Ballagas, autor do Cuaderno de Poesía Negra (1934) e, ao lado de Nicolás Guillén e Manuel del Cabral, um dos estabilizadores da poesia afro-antilhana. ("Essa Negra Fulô" em edição bilíngue é a única peça brasileira da coletânea).

O presente ensaio se propõe a desdobrar essa breve observação de Eulálio sobre o contexto de publicação do livro de Jorge de Lima, historiando, primeiramente, a formação e a consolidação do cânone da poesia afro-americana para, em seguida, examinar sua repercussão no contexto brasileiro dos anos 1930 e 1940 e, em particular na Revista Acadêmica, responsável pela edição do livro. Por fim, em uma segunda parte do ensaio, a ser publicada no próximo número desta revista, busca-se considerar a inserção dos Poemas negros em tal contexto, examinando seu alcance crítico e suas contradições ideológicas.

\section{A consolidação do cânone da poesia afro-americana}

De fato, é nos anos 1940 que se dá essa consolidação e o citado Mapa de 1946 é apenas uma entre outras coletâneas publicadas nessa década, confirmando a previsão de Arturo Torres Rioseco, que em 1942 anuncia a chegada definitiva de um novo movimento na literatura latino-americana, com a emergência de um gênero que ele considera altamente original: o verso negro - "poesia sobre temas negros, usando ritmos negros e composta por membros tanto da raça africana quanto da europeia". ${ }^{3}$

Essa consolidação pressupõe um processo de formação que remete às décadas anteriores. O próprio autor do Mapa já havia publicado, um ano depois 
de seu Cuaderno de versos folclóricos, a Antologia de poesia negra hispano-americana (1935), que responde, juntamente com a Antologia de la poesía negra americana (1936), de Ildefonso Pereda Valdés, e a Órbita de la poesía afro-cubana 1928-1937 (1938), de Ramón Guirao, pelos momentos decisivos da formação do cânone da poesia negra. As três obras encerram um longo processo de colonialismo literário europeu (até então responsável pela elaboração desse gênero de antologia) e abrem "um novo e fundamental capítulo na poesia afro-hispânica: a codificação semioficial do afro-cubanismo” (Mullen, 1988, p.435).

Importa lembrar, com Edward Mullen (1988), que o afro-cubanismo, esse movimento das artes e letras caribenhas, se origina de uma redescoberta da herança africana da região durante os anos 1920 e guarda certos paralelos com o Harlem Renaissance nos Estados Unidos. O estímulo inicial para a literatura negra nas Antilhas, diz ele, é a descoberta das formas musicais populares e da arte africana por artistas europeus do pós-guerra (Picasso, Apollinaire, Stravinsky), embora já houvesse antes um interesse dessa ordem entre os caribenhos, datado da chegada dos escravos no século XVI e manifestado literariamente no romance antiescravista do século XIX, culminando com a publicação de Los negros brujos (1906), do etnólogo cubano Fernando Ortiz. O movimento se desenvolve em duas fases: a primeira, marcada pela participação exclusiva de intelectuais brancos que produzem uma visão altamente pitoresca e exterior da cultura negra; e a segunda, caracterizada pela representação mais séria da experiência negra por escritores como Nicolás Guillén e Reginio Pedroso. A trajetória inteira da voga afro-cubana está refletida na obra do primeiro, que evolui do cômico e do folclórico para uma preocupação com temas e formas mais universais. $\mathrm{O}$ principal período de atividade do afro-cubanismo foi entre 1926 e 1938, sendo, depois de 1940, gradativamente incorporado na corrente geral da literatura caribenha (Mullen, 1988, p.442-3)

De acordo ainda com Miguel Arnedo, ${ }^{4}$ a busca de uma nova definição de identidade cultural nos anos 1920 pelos intelectuais cubanos é uma resposta à crescente dominação dos Estados Unidos em todos os aspectos da vida na Ilha. Influenciados pelos movimentos artísticos, negro e primitivista, da Europa e dos Estados Unidos, os literati da nação logo voltam sua atenção às tradições afro-cubanas, tidas como únicas e exclusivas da cultura local em grande parte não contaminadas pelas influências norte-americanas, sendo fonte particularmente adequada à produção de formas literárias nacionalistas. Assim, entre 1928-1938, forma-se o movimento poético afro-cubano, que pode ser entendido, segundo Kutzinski, como parte de um discurso de mestizaje, fundamental para a construção da identidade nacional cubana desde os escritos de José Martí que, por meio da noção de nuestra América mestiça, buscou convencer os cubanos de todas as cores a lutar em conjunto para a independência, promovendo uma imagem de unidade racial capaz de neutralizar o temor dos brancos de que, em uma Cuba independente, sem proteção da Espanha, os negros se rebelassem para assumir o domínio da Isla. 
Assim como seu reverenciado herói nacional, os intelectuais cubanos dos anos 1920 e 1930 também passam a crer na cooperação entre brancos e negros como precondição indispensável à autonomia do país. Depois da independência (1902), o referido temor persiste e é visto como a principal desculpa para a ocupação norte-americana da ilha. Por isso a solidariedade entre todos os setores da população reaparece como imprescindível à completa autonomia do país. Os afro-cubanistas crem que reforçar a união entre brancos e negros é o melhor meio de fazer que estes últimos se sintam parte do povo oprimido de Cuba, desencorajando assim sua mobilização e ganhando seu apoio à causa nacionalista. Como se vê no programa da Sociedad de Estudios Afro-Cubanos, resumo fidedigno da ideologia dos afro-cubanistas, esses supõem que tal união pode ser alcançada caso se tragam à tona formas culturais mulatas, resultado da coexistência de negros e brancos ao longo de toda a história cubana. ${ }^{5}$ Principal defensor dessa abordagem, Ortiz acredita que as formas culturais verdadeiramente nacionais são produto da incorporação de elementos africanos e espanhóis. Ele se refere, em geral, a todos os poemas afro-cubanistas como mulatos, produto desse processo que simboliza a unidade cultural, mas reconhece alguns como sendo mais autenticamente mulatos do que outros, uma vez que não se trata apenas de empregar a afrocultura cubana como tema e sim como um instrumento por meio do qual se altera as altas formas literárias. Uma dificuldade óbvia enfrentada pelos afro-cubanistas é a incorporação formal, que requer claramente certo grau de proficiência em tais tradições culturais, e a maioria deles não é oriunda dos setores em que elas são cultivadas. Muitos pertencem à classe média e são educados dentro dos padrões da cultura dominante, como é o caso do próprio Ballagas, José Zacarias Tallet e Alejo Carpentier.

Voltando ainda às três antologias fundadoras, ${ }^{6}$ importa observar que a de Ballagas (a primeira impressa e, por isso, um paradigma para esse gênero de publicação) reúne 16 poetas e um compositor de cinco países (Cuba, Porto Rico, Argentina, Uruguai e Espanha), num total de 54 poemas organizados por gênero e tendência, em que predominam os cubanos modernos. Desse modo, a despeito da abrangência do título, trata-se mais de uma antologia limitada à poesia cubana dos anos 1920 e princípios de 1930, do que uma amostra trans-histórica da poesia negra, além de incluir apenas três poetas que podem ser considerados negros (Guillén, Ignacio Villa e Marcelino Arozarena). Viviana Gelado (2010, p.91) chama a atenção para a referência explícita na antologia à raça dos poetas selecionados, dado que expõe "a persistência no campo intelectual cubano desta categoria (sete anos depois da distinção traçada por Mariátegui e Ortiz entre os conceitos de 'raça' e 'cultura' e da substituição da primeira pela segunda)". A antologia traz ainda um importante prefácio "que é ao mesmo tempo uma justificação para e uma explicação sobre o conteúdo do livro" (ibidem), em que Ballagas identifica três direções da poesia moderna, a pura, a folclórica e a social, das quais a segunda é vista como a mais eficaz para descrever e interpretar os aspectos característicos da vida na América. Mas se privilegia o passado folclórico 
de Cuba, o antologista rejeita a então inusitada voga do primitivismo europeu pelo caráter turístico e a-histórico com que a arte africana é flagrada pela "baedeker" e pela "kodak" de Blaise Cendrars, Paul Morand, Gómez de la Serna e outros. Em seus comentários finais, Ballagas define o conteúdo de sua antologia como sendo não a reunião de uma poesia feita por negros, mas sim uma poesia mulata, algumas vezes composta por brancos, o que reflete o legado cultural trazido pela população negra a Cuba.

O autor da segunda antologia, o uruguaio Pereda Valdés, partilha com Ballagas uma condição similar de intelectual branco, classe média e professor universitário, que já publicara anteriormente poemas sobre folclore e cultura negra (alguns até em formas dialetais). Sua antologia vem depois, paradoxalmente, a servir de modelo ao próprio Ballagas no Mapa de 1946. Nela, se reconhece a influência de livros fundamentais à formação do cânone da poesia negra norte-americana, como o de Countee Cullen e o de James Weldon Johnson, este último evocado por Gilberto Freyre no prefácio dos Poemas negros. A antologia reúne 29 poetas de seis países: Estados Unidos, Haiti, Argentina, Cuba, Uruguai e Brasil (incluindo, neste último caso, poemas de Silva Alvarenga, Luís Gama, Franscisco Otaviano, Tobias Barreto e Cruz e Souza). Os Estados Unidos recebem cobertura mais completa, privilegiando-se os poetas do Harlem Renaissance (Sterling Brown e Langston Hughes à frente). Embora tenda, no caso dos poetas de língua espanhola, a privilegiar os de Cuba e Porto Rico, Pereda Valdés rejeita o nacionalismo literário que enforma o trabalho de Ballagas, assumindo uma orientação mais universalista e tornando-se, assim, o protótipo para antologias posteriores. "A passagem do afro-cubano para afro-hispânico já tinha começado. Além disso, banindo o pitoresco dos poemas folclóricos (alguns dos quais ele mesmo havia escrito), dotou o volume com um senso de seriedade e compromisso social jamais visto até então" (Mullen, 1988, p.445). Gelado (2010, p.95) acrescenta que,

graças à ampliação dos recortes histórico e geográfico de sua seleção, Pereda recupera para o corpus da "poesia negra" do continente ao cubano do século XIX Plácido e (mesmo que se possa questionar seus critérios) à produção brasileira. Ainda em relação a Ballagas, Pereda é mais explícito ao assinalar a sobredeterminação do econômico sobre o psicológico como tônica entre os poetas norte-americanos, mesmo que desta maneira reafirme um dos estereótipos "diferenciadores" da produção poética "negra" do "norte" e o "sul" do continente. Ao emitir, por fim, um juízo de valor comparativo desses dois grandes âmbitos culturais, a produção norte-americana lhe parece superior à latino-americana, na qual ressalta, não obstante, a excepcional riqueza de tonalidades e registros presentes na poesia do cubano Nicolás Guillén, e o "contraste mulato" entre a "exuberância retórica" e o "soluço eriçado de asperezas" do brasileiro Cruz e Souza.

Organizada de acordo com critérios históricos mais definidos, a terceira antologia, de Ramón Guirao, é a mais ambiciosa: além dos antecedentes folclóricos (em sua maioria, anônimos dos séculos XVIII e XIX), o livro apresenta poemas retirados da obra de treze poetas cubanos e do compositor Ignacio Villa 
(vulgo Bola de Nieve). Guirao é também um intelectual branco que havia publicado verso afro-cubano e foi solidário com a população negra do país. Seu poema "Bailadora de rumba", escrito em dialeto, é considerado o primeiro poema afro-cubano publicado na Ilha. Por colecionar obras de um movimento já então chegando ao fim, ele opta pela abrangência histórica como um de seus objetivos. $\mathrm{Na}$ introdução, sem desconsiderar os antecendentes do século XVII, afirma que a constituição de um cânone da poesia afro-hispânica como uma produção de matizes diversos ocorre entre as décadas de 1920 e 1930.

Nesse sentido, o marco inicial do debate em torno do surgimento da poética afro-cubana, de acordo com Guirao, está constituído pelo debate político aberto pela criação relativamente recente do regime republicano em Cuba, pela paradoxal sujeição econômica aos interesses de outra nação (que fazem com que o regime colonial e as práticas semiescravistas se prolonguem sob novas formas) e pela ânsia de afirmar, nesse contexto complexo, o surgimento de uma nacionalidade. Para a definição dessa nova poética, e retomando uma tradição recente, mas já consagrada e sedimentada, Cuba conta com um corpus científico (construído por Fernando Ortiz), um corpus poético (reunido [...] por Ballagas e Juan Ramón Jiménez, e comentado criticamente por Marinello) e um contato efetivo (material e histórico) com o "homem negro".

Essas premissas básicas servem a Guirao para questionar os valores falsos ou encobridores de interesses coloniais do negrismo primitivista europeu; para situar a produção afro-cubana no continente como "feito parcial [de] categoria universal" [...]; e para afirmar, em última instância, como havia proposto Marinello, o caráter genuinamente nacional dessa produção. [...] Dotada de elementos positivos (como a persistência da anedota e o uso da jitanjáfora e da onomatopeia), "nem sempre antipoéticos", e de outros mais questionáveis (como as atitudes "demasiadamente elementares ou infantis, [...] caricaturescas"), a "poesia afro-cubana" é já imprescindível "no embasamento da futura poesia cubana integral", posto que não lhe faltam nem a perspectiva histórica que lhe dá sua tradição folclórica, nem a projeção de futuro que lhe dá a exploração de uma "lírica bilíngue de espanhol e dialetos africanos", e de um molde métrico de invenção afro-cubana: o son. (Gelado, 2010, p.96-7)

Quando publica sua Órbita, embora Guirao veja o verso afro-cubano já como um dado histórico, um momento congelado na história literária, o interesse pela cultura negra e a sua expressão literária no mundo hispânico passa a crescer de forma constante nas próximas décadas. Algumas mudanças fundamentais têm lugar, no entanto, no modo como os antologistas vêm a lidar com seu material. A visão centrada no Caribe do primeiro Ballagas e Guirao é gradualmente substituída por antologias que ressaltam a relação coextensiva de escritores negros e não negros que buscam poetizar a experiência negra e explorar os padrões comuns partilhados pelos padrões míticos da diáspora negra. Livros como José Sanz y Diaz, Lira negra (1945), Juan Felipe Torufio, Poesia negra: ensaio e antologia (1953), Simón Latino, La poesia negra (1956) e o citado Mapa de 1946 de Emilio Ballagas, revelam uma ambição verdadeiramente continental ao reunirem amostras de poetas de todas as Américas. Para todos es- 
ses editores, coloca-se a questão da autenticidade (podem brancos escrever poesia negra?), concluindo-se que a experiência americana da mestiçagem cultural fornece a resposta: “não se trata aqui de poesia negra em toda sua pureza, mitologia e originalidade africana", diz o mesmo Ballagas (1946, p.8-9), mas sim "poesia de contraste e assimilação de culturas; uma suma de poesia afro-americana cujo caráter é o de ser uma arte de relação". A inclusão de novos poetas, alguns dos quais negros, como Candelario Obeso e Jorge Artel, também é um aspecto importante dessas antologias.

Neste repasse já bastante extenso das principais antologias que definiram o cânone da poesia negra, cabe, por último, falar desse Mapa em que Jorge de Lima é incluído com "Essa negra Fulô". Sem mais, recorro a passagens da análise de Gelado sobre tal antologia de 1946:

Ilustrado por Ravenet, pintor já consagrado nessa temática, o Mapa está organizado por países e regiões (Estados Unidos, México e América Central, as Antilhas e a América do Sul) e inclui uma seção dedicada à poesia de motivo negro escrita por espanhóis entre os séculos XVII e XX. [...] [A] maior parte da produção em inglês (o slang), francês (o créole) e português aparece na língua original, além de traduzida para o espanhol; assim como aparecem as versões publicadas em inglês e português do poema. [...] Uma vez estabelecido o cânone $[\ldots]$, Ballagas poderá ocupar-se de selecionar com o objetivo de expor uma diversidade de acentos, em correspondência com a diversidade racial e cultural do continente [...] estabelecendo analogias entre a produção de diversos países. [...] As linhas de análise desenvolvidas por Ballagas na introdução levam-no à conclusão de que "é improcedente o emprego da expressão 'tema negro' para caracterizar essa poesia”. E também (corrigindo Guirao?), que a diversidade de acentos em consequência da "mestiçagem" e da "interculturação" é tão grande que tampouco pode falar-se de "um modo único" [...]. Por outro lado, ainda que afirme na introdução que "a poesia mulata tem dado mostras muito estimáveis dentro da arte popular e da arte culta", na nota que precede os "cantos anônimos" cubanos esclarece: "nossa intenção mais que folclórica é culta, ainda que nem sempre tenhamos podido dar em cada país com a nota mais espiritual" [...]. Consequentemente, é possível afirmar que tanto Ballagas, como Guirao e Pereda Valdés entendem o popular como folclórico (o popular já estilizado e, de certa forma, cristalizado no passado) e o incorporam como dado da tradição, como antecedente. No caso de Ballagas, em especial, sua opção pelo registro culto se relaciona, em parte, com sua falta de perspectiva histórica no tratamento dos materiais recompilados, mas sobretudo com uma tomada de posição deliberada. Como seus contemporâneos Carpentier e Mário de Andrade, que defenderão um aproveitamento sinfônico do material popular e folclórico no âmbito musical, Ballagas não só não romperá com a distinção entre alta cultura e cultura popular, mas também adotará uma posição favorável à primeira. (Gelado, 2010, p.100-1)

É ainda Gelado (2010, p.101) quem chama a atenção para o "silêncio absoluto do movimento de vanguarda cubano", bem como das introduções do Mapa e demais antologias aqui comentadas, sobre o "primitivismo nova-iorqui- 
no (de corte muito semelhante ao europeu)". Nota igualmente que a incorporação da produção dos poetas afro-americanos vai se fazer "sem menções claras ou enfáticas ao movimento do Harlem Renaissance nem às diferenças político-ideológicas que distinguiriam uma proposta da outra". A partir daí, conclui que

a "omissão" é altamente significativa, pois a produção em terra ianque de uma poesia que expressa como poucas a raiz trágica do afro-americano é o primeiro exemplo citado por Marinello em seu artigo pioneiro [...]. Essas opções me parecem índices claros da desconfiança e paralela ineficácia prática com que, no plano político, a elite caribenha trata, nesse período, do imperialismo norte-americano, e do esforço persistente dos poetas e intelectuais vinculados ao movimento de vanguarda para avaliar essa produção estética separada do contexto político (premissa absurda no que se refere aos poetas do Harlem Renaissance). Em tal sentido, a acuidade com que se questiona no âmbito afro-hispânico o primitivismo europeu, como modismo que encobre a expansão dos impérios coloniais, aparece, paradoxalmente, sob a forma de silêncio em relação ao teor e função estético-ideológica do primitivismo norte-americano. (ibidem, p.101-2)

Partindo deste último comentário, é curioso pensar (nos próprios termos de Gelado, mas num contexto literário bem diverso) as condições de produção e as sobredeterminações ideológicas dos Poemas negros de Jorge de Lima, cuja concepção é fruto do confronto entre a poesia negra praticada até então pelo poeta alagoano e moldada pelas concepções de Freyre; o tratamento dado ao tema pelo modernismo em diálogo com as vanguardas europeias; e certa recepção da poesia afro-cubana (em especial Guillén) e do Harlem Renaissance (com destaque para Hughes) por ocasião da composição do livro de 1947. Para isso, seria preciso ainda rastrear indícios dessa recepção no contexto literário brasileiro da época. Na impossibilidade de uma contextualização mais ampla, vou circunscrevê-la ao debate presente na Revista Acadêmica, que responde, afinal, pela publicação dos Poemas negros.

\section{A Revista Acadêmica e o contexto de emergência dos Poemas negros}

Registre-se, antes, algo do contato de Jorge com um dos antologistas hispano-americanos mencionados atrás: Pereda Valdés, que manteve intenso contato com o Brasil. Há uma carta de Ildefonso Pereda Valdés a Jorge, reproduzida no Jornal de Alagoas de 17 abril de 1928, em que o uruguaio registra o recebimento e a leitura dos Poemas (1927) que Jorge de Lima lhe enviou e sobre o qual dirá, "[r]esumiendo: su libro es uno de los más hermosos que he recebido del Brasil". 'Destaca ainda no livro, "por afinidad negreira", o poema "Xangô", prometendo traduzi-lo para a sua Antología negra, que preparava para o ano seguinte, assim como prometia enviar ao poeta alogoano, proximamente, um livro que então elaborava e que também se chamaria... Poemas negros! Ao que parece, Pereda Valdés não chegou a incluir uma tradução de "Xangô" nessa que deve ser sua Antologia de la poesia negra americana de 1936. Das antologias inventariadas, Jorge de Lima só apareceria mesmo com "Essa negra Fulô" no Mapa de Ballagas dez anos depois. 
Passando, agora, ao debate em torno da poesia negra norte-americana nas páginas da Revista Acadêmica, vale lembrar que ele se inscreve numa tendência maior dos anos 1930, que assiste à projeção dos estudos afro-brasileiros, às comemorações do cinquentenário da abolição em 1938 e a outros acontecimentos relevantes. A ênfase dada aos estudos afro-brasileiros à época leva, inclusive, Caio Julio César Tavares, em artigo estampado no n.18 da revista, a responder ao que então já se denomina, "meio sério, meio rindo", "mania" do negro ou "moda" desses estudos. Indignado, contra-ataca Tavares: "Ora não há moda sem causas profundas. Simular a inexistência de causas para evitar os resultados que elas condicionam, é o processo habitual e antigo dos que não desejam tantas causas profundas... (A 'moda' dos índios e dos africanos” RA, n.18, 1936/37). ${ }^{8}$

$\mathrm{Na}$ verdade, além dos contos, poemas e ensaios especificamente literários publicados na Revista Acadêmica, há estudos de natureza antropológica, sociológica e histórica que envolvem diretamente o negro, a exemplo das colaborações de Arthur Ramos (o psiquiatra, folclorista, antropólogo e etnólogo, idealizador da teoria da democracia racial, a qual voltaria a despontar no prefácio de Freyre aos Poemas negros, conforme veremos), mas incluindo ainda nomes menos lembrados como Sergio A. Vieira ("A questão das raças", n.42, fev. 1939) e Reginaldo Guimarães ("Notas sobre o culto de Oxalá", n.17), além da republicação do estudo de Alberto Torres, "Em prol de nossas raças" (n.35, maio 1938). Destaque-se, ainda, uma entrevista feita com o Prof. Franklin E. Frazier, sociólogo e chefe da seção de Ciências Sociais da Howard University (Washington, DC), de passagem pelo Rio de Janeiro, na companhia de outro antropólogo afro-americano, Prof. Turner (da Universidade de Fisk, Nashville, Tenessee), a caminho da Bahia onde permanece por cinco meses, com uma bolsa da Fundação Guggenheim, desenvolvendo pesquisa sobre sua especialidade: "a família negra como um meio de estudar o processo de assimilação racial" ("Sobre o negro nos Estados Unidos", n.52). Na entrevista, Frazier fala sobre a situação educacional, profissional e econômica do negro nos Estados Unidos; elogia os avanços dos estudos afro-brasileiros, vendo neles um meio de aproximar ainda mais brasileiros e norte-americanos. Destaca, nesse sentido, o trabalho de Donald Pierson, na Escola Livre de Sociologia e Política de São Paulo, com estudo então inédito sobre as religiões negras, desenvolvido por dois anos na Bahia. Indagado pelos editores da revista a respeito das diferenças e semelhanças entre o negro americano e o brasileiro, Frazier estabelece duas oposições bastante representativas que repercutem também no plano da arte e da literatura, e contra as quais parece se voltar Gilberto Freyre no prefácio ao Poemas negros:

Nos Estados Unidos, a existência de uma "linha de cor" tem tendido para criar uma solidariedade entre os negros e os de sangue misturado, o que tornou a raça negra extremamente "race conscious". A imputação de inferioridade racial estimulou os negros a vencer as suas incapacidades. No Brasil parece-me não existir esta solidariedade racial e esta consciência de raça, e os de sangue misturados, mulatos e pardos, não se unem muito aos realmente negros. Se existisse 
uma "linha de cor" aqui no Brasil, evidentemente ela se manifestaria por meios muito sutis e é baseada mais em preferências e antipatias pessoais do que em práticas institucionalizadas.

A segunda observação diz respeito aos negros puros e aos de sangue misturado. Nos Estados Unidos, bem como no Brasil, os mulatos e outros tipos de sangue misturado, são encontrados em maior número nas classes mais altas do que os negros puros. Parece-me que apesar das diferenças na situação racial dos dois países, o mesmo processo de seleção é responsável pela situação. Nos dois paí-ses, os de sangue misturados tem tido assim mais facilidade para ascensão na pirâmide social do que os de sangue inteiramente negro. Nos Estados Unidos, porém, grandes massas de negros puros estão recebendo educação completa e assim se elevando a camadas sociais mais altas. (RA, n.52)

Os editores concluem a entrevista notando que, pelas palavras do entrevistado, é possível depreender com facilidade a grande evolução que vinha experimentando a situação do negro norte-americano, sobretudo com Roosevelt, cuja esposa pode ser considerada "uma das maiores advogadas da igualdade de direitos para pretos e brancos na grande democracia americana, dando o mais completo apoio a todos os empreendimentos neste sentido [...] A sombra de Lincoln se confunde com a presença de Roosevelt" (RA, n.52).

Quanto aos estudos históricos publicados na Revista Acadêmica, são exemplo a resenha do livro de Adherbal Jurema sobre as "Insurreições negras no Brasil" (n.14); o "Panorama da escravidão", de Nelson Werneck Sodré (n.34, abr. 1938); as "Juntas de alforria", de Artur Ramos (n.33); a reprodução de trechos de $O$ abolicionismo de Nabuco (n.35) e de documentos históricos como uma "Escritura de venda e escravos" (n.24-25).

Somem-se, também, notícias sobre acontecimentos políticos e culturais ligados à cultura africana, como a de José Bezerra Gomes, no n.14 (1935), sobre o $1^{\circ}$ Congresso Afro-Brasileiro de 1934 no Recife, sob liderança de Freyre que, "entre outros serviços, elucidou o erro em que muita gente caia de ver o negro através do escravo e separou um do outro mostrando que, embora escravizado e oprimido pelo branco, o negro não perdeu as suas características de raça, não deixou de conservar suas tradições e costumes, herdados e trazidos da África distante e livre". Acrescente-se a esse inventário a nota sobre o "Antirracismo em Lima", discutindo a proposta de Cuba na conferência de Lima e a posição do Brasil, estampada no n.35, bem como a notícia sobre a "Conferência Panamericana, em dezembro de 1938, no n⿳⺈.41, das quais se pode ainda aproximar os comentários do já citado Caio Júlio Tavares sobre os "Estudos Afro-brasileiros” (RA, n.21).

Fazendo a passagem dos estudos histórico-sociológicos para os artístico-literários, a Revista Acadêmica traz um ensaio do mesmo Adherbal Jurema sobre "O negro na América", que parte do livro de Benjamin Brawley ( $A$ short history of the American Negro), a fim de tratar, historicamente, do

formidável esforço que o negro norte-americano fez para quebrar as cadeias da escravidão. Aliás, no país mais democrata das Américas, a luta de classes e 
de raças assumi[u] e ainda continua a assumir proporções épicas. O negro dos Estados Unidos, nas suas manifestações de rebeldia, foi mais radical do que o afro-brasileiro. Isto se explica diante da maior segregação que ele sofria, o que contribuiu, de maneira evidente, para o desenvolvimento de uma cultura própria. Daí o nível intelectual do negro da América do Norte ser superior ao da América do Sul, onde a miscigenação quase que aboliu as fronteiras culturais. (RA, n.11, 1935)

Jurema fala, ainda, das insurreições dos negros norte-americanos (similares às que ocorreram na Bahia no século XIX, mas mais organizadas que estas); dos versos exemplares de Hughes em "Eu também sou a América” e dos blues como protesto contra os sofrimentos diários. Desmistifica a imagem que então se fazia do Harlem como paraíso negro (como Paul Morand e outros autores de literatura de viagem), argumentando com o jornalista Erwin Kirsch que empresas importantes, cinemas, cabarés, transportes, casas de jogos e bebidas do Harlem são de propriedade branca. "Pode-se concluir deste depoimento que o Harlem é mais um meio comercial que os homens brancos usam para explorar os sentimentos estéticos e a força física dos negros, chamando a atenção dos viajantes requintados e desenvolvendo, assim, a indústria do turismo" (ibidem).

Passando à produção artístico-literária “negra” estampada na revista, vale registrar o destaque dado ao estudo de Mário de Andrade sobre o Aleijadinho, como a resenha de Múcio Leão no n.18. Quanto aos contos e poemas de temática negra, destaque-se a reprodução de "Pai contra mãe" (n.45) em homenagem ao centenário de Machado de Assis; a publicação de "Foi sonho", de Mário de Andrade (n.15); a de "Senzala", de Odorico Tavares; de "O quilombo de Manoel Congo", de Marcos (na verdade, Carlos Lacerda), no n.11; de alguns poemas de Hughes ("Suicídio", no n.14, e "Casa no mundo", no n.43), que a Revista Acadêmica foi a primeira a traduzir aqui, e do poema de Frank Marshall Davis ("Que queres, América?”, na versão de Abelardo Araújo Jurema e Odorico Tavares). Há a publicação dos poemas do próprio Jorge de Lima: o "Bangüêe" (que integraria os Poemas negros), a republicação de "Essa negra Fulô", com ilustrações de Di Cavalcanti, e a versão para o inglês de "Cantigas" ("Songs") feita por Ruth M. Anderson para integrar uma antologia a ser publicada pela Hispanic Society of America e que é reproduzida no n.49 da revista com uma bela ilustração de Santa Rosa.

O n.52 traz também o texto (em espanhol) de um postal enviado a Jorge por Waldo Frank, reiterando o elogio a Poemas depois de relido:

New York, 15-10-40

Querido Jorge de Lima:

Hace tempo, le agradecí el envio de su hermoso libro de Poemas. Hoy, le doy outra vez mis gracias, porque acabo de re-leerlos.

Su amigo y Hermano

Waldo Frank 


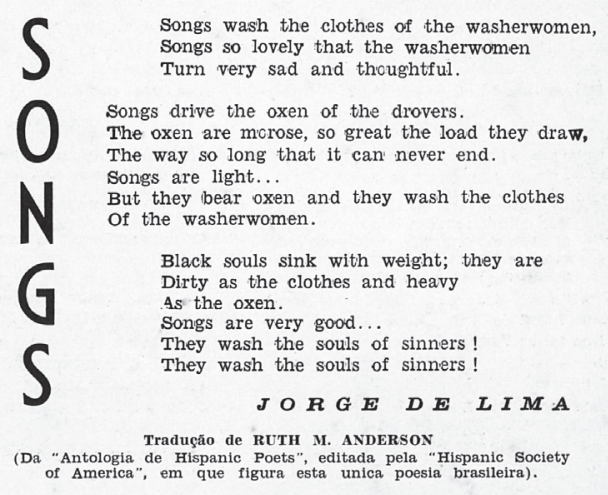

Ilustração de Santa Rosa para a publicação do poema "Songs" ("Cantigas") de Jorge de Lima, Revista Acadêmica. n.49. Rio de Janeiro, maio 1940.
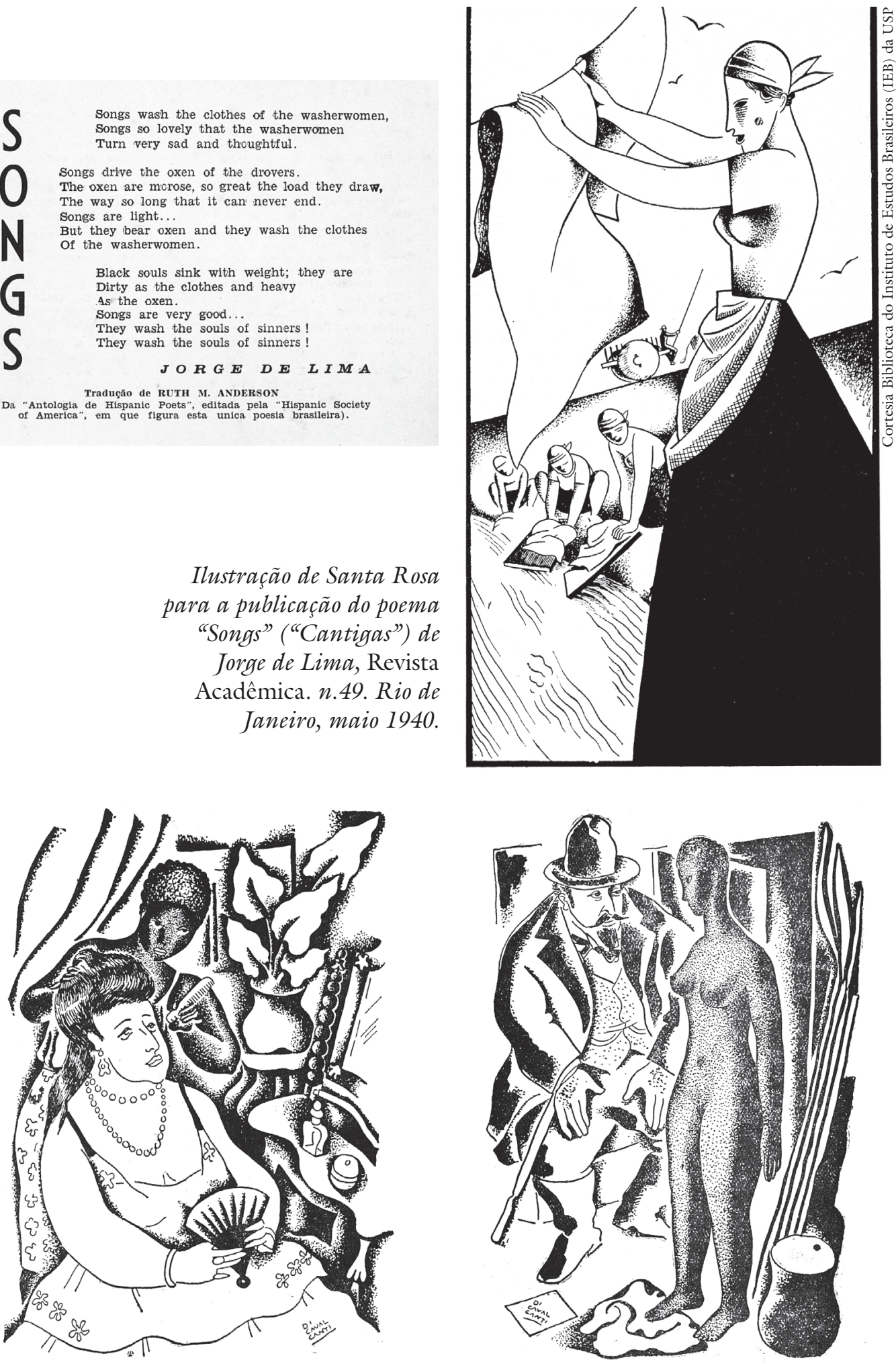

Ilustração de Di Cavalcanti para o poema de Jorge de Lima, "Essa negra fulô". Revista Acadêmica. n.63. Rio de Janeiro, maio 1943.



Ilustração de Di Cavalcanti para o poema de Jorge de Lima, "Essa negra fulô". Revista Acadêmica. n.63. Rio de Janeiro, maio 1943. 
Passando aos estudos literários, há um artigo de Amadeu Amaral, "A literatura da escravidão", em que, partindo de um comentário sobre o machadiano "Caso da vara", atribui retroativamente, como base em Melo Morais e José Veríssimo, o título de "tradutor ou principal introdutor do negro em nossa literatura" ao poeta maranhense Trajano Galvão (1830-1864), mas reivindicando que esse título seja repartido com "o paulista José Bonifácio, o moço, que desde 1850 se interessava pela sorte dos escravos, com acentos de que só talvez se encontre a consonância, mais tarde, em Castro Alves" (n.57, ago. 1941, e n.58, out. 1941). Mas os dois ensaios de maior interesse na revista, para nossos propósitos, são o de Gilda de Melo e Souza (que então assinava o nome de solteira) e o de Aida Cometa Manzoni.

Em "Poesia Negra Norte-Americana", Gilda Morais Rocha reconhece a "enorme distância que separa essa atual Renascença Negra de qualquer das manifestações poéticas anteriores", na medida em que reflete "muito mais profundamente o sentimento íntimo da raça". Não recorrendo mais à "eclosão da poesia melodramática e exibicionista, descuidada na forma, tão frequente pela época da abolição, ou ao pitoresco superficial e gracioso das poesias de dialeto", a "poesia negra hoje em dia atravessa, ao contrário, um período de construção consciente cujo objetivo principal é, como proclama o Manifesto redigido por Langston Hughes, realizar corajosamente as personalidades de cor, indiferentes ao público branco ou negro". Gilda Rocha, entretanto, adverte:

essa atual poesia negra que Alain Locke considera a melhor representação artística do negro do mundo só foi possível devido à experiência poética que a precedeu e a um momento social particular que permitiu ao negro sua plena realização. O período anterior à Renascença - esse longo período que vai do aparecimento de Phillis Wheatley, na segunda metade do século dezoito, até o começo deste século - foi um período preparatório em que o negro assimilou as características da América branca, enriquecendo-as com a sua contribuição peculiar à civilização americana [...]. Foi uma época de 'capitalização de energias' em que recolheu dentro de si as reações produzidas pelo contato duma cultura que não era a sua e de uma sociedade que o excluía do seu convívio. A revolta do povo oprimido, o sentimento de injustiça, a fuga no 'humour', a exaltação religiosa, a interpretação ingênua da Bíblia, a deformação do inglês, tudo isto que o negro iria mais tarde transformar em elementos característicos de sua poesia já se encontra delineado [...] Mas o negro que se preparava para lançar à América sua mensagem, teve que esperar um momento oportuno. Este se apresentou quando a grande migração do Sul para o Norte, onde as fábricas o atraíam, chamou a atenção sobre ele, e obrigou o branco a encará-lo como um agente livre que promoveu melhores oportunidades, como uma força social e econômica de extrema importância. (RA, n.59, jan. 1942)

A ensaísta dá destaque, no Harlem Renassaince, a figuras importantes como James Weldon Johnson, Claude McKay, Jean Toomer, Countee Cullen, Sterling Brown e, sobretudo, Langston Hughes, observando que, com "poucas exceções, são quase todos aventureiros que desprezam a burguesia e os precon- 
ceitos e adotam uma atitude feroz diante da sociedade" (RA, n.59, jan. 1942). São, fundamentalmente, mais artistas que os poetas anteriores, pois não se contentam apenas em explorar seus sentimentos, mas também a técnica poética:

Enquanto a antiga escola do dialeto seguia só o que lhe ditava o ouvido, Sterling Brown, Lucy Williams e Langston Hughes estudam minuciosamente o sotaque do meio descrito e conseguem efeitos que não derivam apenas do inglês estropiado, mas do próprio sentimento da raça que aí se expressa. (RA, n.59, jan. 1942)

O mesmo destaque dado por Gilda Rocha à poesia negra de Langston Hughes e do Harlem Renaissance está no ensaio de Aida Manzoni, que entretanto busca ampliar seu escopo com a pretensão de cobrir a produção afro-poética de toda a América.

Publicado, antes, em Nosotros (Buenos Aires, n.44 e 45, a. 4, $2^{\text {a }}$ época, nov.-dez. 1939), “Trajetória do negro na poesia da América” saiu em duas partes, nos números 51 (set. 1940) e 60 (maio 1942). Manzoni começa com uma afirmação discutível ao destacar o privilégio dos Estados Unidos de ter trazido o negro à poesia e reconhece em Vachel Lindsay o primeiro a se ocupar do tema, com seu The Congo (1915), embora logo em seguida afirme (meio confusamente) que, antes de esse poeta branco se sentir "atraído pelo exotismo do filho da África, aparecem nos Estados Unidos os primeiros poetas de cor que cantam como tal. É uma mulher, Phyllis Wheatley, uma escrava africana, a primeira expressão poética da raça. Seus poemas datam de 1770". Em seguida, evoca Paul Lawrence Dunbar e, entre outros tantos “expoentes de valor", James Welton Johnson, que influenciaria muitos "poetas de cor" e, em 1922, organizaria uma antologia de poesia negra norte-americana, reunindo a produção de uma centena de nomes. Na época que lhe é contemporânea, Manzoni destaca Countee Cullen, que, afora seus três volumes de poesia, também publicou uma antologia; Richard Bruce e Streling Brown, de quem um crítico de valor afirmou que "ninguém penetrou mais profundamente na canção negra”. Mas, sem dúvida alguma, o mais famoso e justamente celebrado é Langston Hughes, que estreia em 1926 com The Weary Blues:

Até então, ninguém interpretara assim a alma da raça, dando uma autêntica expressão a sua dor de escravos e despertando a consciência de sua condição social. Ninguém, até então, trouxera a tão alto grau de universalidade o tema negro, e dera à poesia tal sentido revolucionário e tão intenso calor humano. Sem sentimentalismos ridículos nem falsos alardes de rebeldia; com voz serena, consciente da missão que lhe cabe desempenhar, cantara primeiro a raça oprimida para ampliar depois a sua mensagem a todos os humilhados e ofendidos. (RA, n.5l, set. 1940)

Repetiu-se na Europa a acolhida favorável que a literatura norte-americana dispensara a Langston Hughes. "Um pouco por exotismo e também obedecendo a uma imperiosa necessidade de evasão, os povos do ocidente procuram na arte negra os novos elementos que eles são incapazes de criar” (RA, n.60, 
maio 1942). Assim, antes de passar à poesia negra latino-americana, Manzoni detém-se um pouco na exploração da temática negra na Europa, tanto nas artes plásticas (cubismo, Picasso, Braque, Derain e outros “fauves", todos precedidos por Gauguin, além da apologia feita por Apollinaire num prefácio de esculturas negras em que acentua sua predileção por essa arte), quanto na literatura, começando com a Anthologie Nègre, um "interessante resumo do folclore africano" de Blaise Cendrars, e enumerando ainda Paul Morand (Paris-Tombouctou e Magie Noire), André Gide (Voyage au Congo) e Paul Reboux (Romulus Concou), entre outros escritores de prestígio. Manzoni nota que o negro, nessas obras, "é um personagem pitoresco, figura artística e não realidade humana. Porque a esses escritores ele não interessa em sua condição social, mas como elemento exótico, pela riquíssima seiva que traz" (RA, n.60, maio 1942). No entanto, reconhece que, embora seja absolutamente exterior essa visão do negro, sua importância é considerável porque influi poderosamente sobre a literatura dos povos latino-americanos". Afirma, em seguida, que

as letras da América Latina foram enriquecidas pela contribuição de alguns poetas de cor desde o século XVIII. Os nomes do mexicano José Vasconcelos, o negrinho poeta, o primeiro homem de cor que canta no continente; o dos cubanos Gabriel de la Concepcion Valdés, Juan Francisco Manzano, Agustin Baldomero Rodriguez, Ambrosio Echemendia e Antonio Medina, e o dos brasileiros Silva Alvarenga e Cruz e Sousa são expoentes de autêntico valor literário. Mas todos eles esqueceram, nos seus escritos, a cor da própria pele. Não foram interpretes de sua raça. Ao adquirirem um grau de cultura superior, igualaram-se aos brancos e cantaram como eles. (RA, n.60, maio 1942)

Reconhece, ainda, que no século XIX o tema da escravidão ocupou os poetas latino-americanos, a exemplo, de um ponto de vista absolutamente romântico, do cubano José Maria Heredia, Domingo del Monte, outros tantos cubanos, além do dominicano Francisco del Monte (mas não chega a citar Castro Alves). Nota, entretanto, que em todos esses poetas "o negro foi utilizado como elemento exótico. [...] Por isso, essas obras nada têm a ver com a poesia negra que irá surgir no século XX” (RA, n.60, maio 1942), no qual destaca Ramón Guirao, Alejo Carpentier, o porto-riquenho Luiz Palés Matos, Jose Zacarias Tallet, Emilio Ballagas e, acima desses e outros tantos, Guillén:

Nicolás Guillén ocupa na poesia afro-antilhana o mesmo lugar que Langston Hughes na poesia negra norte-americana. [...] Mulatos ambos, chegaram ao tema negro por um imperativo de seu próprio sangue [...] Como Langston Hughes, ele compreendeu que o homem de cor não é apenas elementos estético valioso, espetáculo digno de consideração artística, mas também realidade humana, homem sujeito a uma servidão iníqua que oprime há séculos. (RA, n.60, maio 1942)

Esse alinhamento dos dois poetas passa a figurar como parâmetro na superação da visão exterior e exótica do negro, em direção ao social. No caso de Guillén, embora não haja, como ocorreu com Hughes, a tradução de seus po- 
emas na Revista Acadêmica, sabe-se da repercussão de sua obra, sobretudo por ocasião de sua estada no Brasil no mesmo ano da publicação dos Poemas negros (1947). Sobre essa repercussão, diz Vera Lins (2011, p.100):

Manuel Bandeira faz um discurso em sua homenagem na Academia Brasileira de Letras, na quinta feira, 20 de novembro, e é respondido pelo cubano, que fala de Castro Alves e Machado. O discurso é reproduzido no Jornal do Comércio no domingo, dia 23, e depois publicado nos Cadernos de Cultura do MEC, de 1954, De poetas e poesia. Drummond traduzira seu poema "Sones" ("Sons") no meio da página do Diário Carioca no ano anterior (27/01/1946), entre uma crônica de Bandeira e uma crítica de Antonio Bento sobre Graciliano Ramos e Leskoschek. Numa nota apresentando o poeta, vê nele traços de Villon e Baudelaire e diz que deu foros literários à canção folclórica. Jorge de Lima escreve sobre ele, em O Globo (3/11/1947). José Lins do Rego também, dois artigos no mesmo jornal (30 de outubro e 3 de novembro de 47) e Álvaro Moreyra, na Tribuna Popular (19 de fevereiro de 1948). Guillén hospeda-se na casa de Portinari, visita o ateliê de Flávio de Carvalho. Sérgio Milliet, crítico e poeta, fala dele no Estado de São Paulo $(5 / 12 / 47)$, traduzindo-lhe alguns versos do poema "West Indies Ltd.", comenta sua obra reunida, El son entero, dizendo que combina folclore com um lirismo requintado. Mas em Santos cancelam uma apresentação sua, é proibido de falar. Ainda Murilo Araújo escreve sobre ele o artigo "A revolta que canta", na revista Leitura, em 1962, quando passa de novo pelo Brasil e é lançada em português sua Antologia poética, traduzida por Ari de Andrade, pela Editora Leitura. Neste número, a revista publica também um texto seu, curto e em prosa: "Impressões do Brasil", escrito na volta da última viagem, em que conta sobre conversas e contatos com brasileiros na ruas, nos táxis.

Creio que esses dois parâmetros, representados pela poesia de Guillén e pela de Hughes, à luz da consolidação do cânone da poesia afro-hispânica e afro-americana, atuaram de forma decisiva na reconfiguração da poesia negra de Jorge de Lima, no sentido de aprofundar sua visada social, superando, assim, a dimensão de exterioridade e exotismo dos primeiros livros, e buscando, quem sabe, pleitear com isso maior inserção no debate internacional sobre o tema (embora, em princípio, sua ambição com o livro não fosse além do mecanismo mais convencional de consagração local, como se verá). Talvez haja algo mais do que mera pretensão provinciana de Freyre no prefácio aos Poemas negros, quando fala, meio hiperbolicamente, de Jorge de Lima como alguém “em quem a América inteira sente um poeta largamente seu pela cordialidade crioula e pelo lirismo cristão, franciscano, fraternal..." (Lima, 1974, p.158).

Continua

\section{Notas}

$1 \mathrm{O}$ presente artigo corresponde a uma nova versão de um ensaio publicado primeiramente com o título "Notas sobre os Poemas negros e o diálogo poético de Jorge de Lima e Gilberto Freyre” (in Kosminsky et al., 2003, p.347-60). Depois, foi ainda pu- 
blicado com o título "Poemas Negros: um diálogo poético de Jorge de Lima e Gilberto Freyre” na Revista USP, São Paulo, n.59, p.224-31, set./nov. 2003).

2 Alguns poemas já haviam sido recolhidos em coletâneas anteriores: Poemas (1927), Novos poemas (1929) e Poemas escolhidos (1932). Todas as menções feitas aos poemas de Jorge de Lima referem-se à edição Poesias completas (Lima, 1974).

3 Nas décadas seguintes, a terminologia de Rioseco se modifica, com negro sendo substituído por variantes, como negroide, negrista, afro-cubana, mulata, até culminar, nos anos 1970, no termo afro-hispânico para referir amplamente a literatura escrita por ou sobre os afrodescendentes do mundo falante de espanhol (cf. Mullen, 1988, p.435).

4 Todo este parágrafo é uma retomada do que vem exposto em Arnedo (2001, p.1-4).

5 A Sociedad de Estudios Afro-Cubanos, fundada em 1936, é presidida por Fernando Ortiz e inclui entre seus membros os afro-cubanistas Emilio Ballagas, Ramón Guirao, Nicolás Guillén e Marcelino Arozarena.

6 Retomo aqui, em síntese, os comentários feitos por Mullen e Gelado nos ensaios citados.

7 Carta reproduzida e traduzida por Gênese de Andrade em Teresa. Revista de Literatura Brasileira, n.3. São Paulo: DLCV/USP (Área de Literatura Brasileira)/Ed. 34, 2002, p.64-5.

8 A Revista Acadêmica não traz em geral o número de página e nem todos os números indicam, precisamente, o mês e o ano de publicação. A nota bibliográfica será feita de forma abreviada, RA, no corpo do texto, seguida do número do exemplar e da indicação do mês e do ano quando houver. Consultamos todos os números da revista constantes do acervo do IEB/USP.

\section{Referências}

ALMEIDA, J. M. G. de. A tradição regionalista no romance brasileiro. Rio de Janeiro: Topbooks, 1999.

ARAÚJO, R. B. de. Guerra e paz: Casa-grande \& senzala e a obra de Gilberto Freyre nos anos 30. Rio de Janeiro: Ed. 34, 1994.

ARNEDO, M. "Afrocubanista" Poetry and Afro-Cuban Performance. The Modern Language Review, v.96, n.4, p.1-4, Oct., 2001.

ARRIGUCCI JUNIOR, D. Humildade, paixão e morte: a poesia de Manuel Bandeira. São Paulo: Companhia das Letras, 1990.

BALlAGAS, E. Cuaderno de Poesía Negra. La Habana: Imprenta “La Nueva”, 1934. . Mapa De La Poesía Negra Americana. Buenos Aires: Pleamar, 1946.

BASTIDE, R. Doçura do Leite das Negras. Letras e Artes, São Paulo, 22 fev. 1948.

BOSI, A. História concisa da Literatura Brasileira. São Paulo: Cultrix, 1975.

. Sob o signo de Cam. In: - Dialética da colonização. São Paulo: Companhia das Letras, 1995. p.254-61. . Poesia versus Racismo. In: . Literatura e resistência. São Paulo: Companhia das Letras, 2002. p.163-85. 
CHIARELLI, T. Segall realista: algumas considerações sobre a pintura do artista. In: Catálogo da exposição "Segall realista”. São Paulo: Centro Cultural Fiesp/Galeria de Arte do Sesi, 29 de janeiro a 16 de março de 2008, p.23.

D'ANDREIA, M. S. A tradição re(des)coberta: Gilberto Freyre e a Literatura Regionalista. Campinas: Ed. Unicamp, 1992.

EULÁlIO, A. A obra e os andaimes: os trinta anos da morte de Jorge de Lima. In:

Escritos. Campinas: Ed. da Unicamp; São Paulo: Ed. da Unesp, 1992. p.481.

FITZ, E. E. The Black Poetry of Nicolás Guillén and Jorge de Lima: A Comparative Study. Inti: Revista de Literatura Hispánica, v.1, n.4, article 13, 1976.

GELADO, V. Primitivismo y vanguardia: las antologías de "poesía negra” hispanoamericana en las décadas del 30 y del 40. Tinkuy, Montréal, n.13. Junio 2010. Disponível em: <dialnet.unirioja.es/servlet/fichero_articulo?codigo $=3304240 \&$ orden $=0>$. Acesso em: 5 maio 2011

ILARI, R. Os Poemas Negros de JL. Nossa América, São Paulo, p.8-13. nov.-dez. 1991.

IVO, L. Rol de Insulíndias. In:__. Poesia observada. São Paulo: Duas Cidades, 1978.

KOSMINSKY, E. V.; PEIXOTO, F. A.; LÈPINE, C. (Org.) Gilberto Freyre em quatro Tempos. São Paulo: Editora Unesp; Edusc; Fapesp, 2003.

LIMA, J. de. Poesias completas. Rio de Janeiro: José Aguilar; Brasília: INL, 1974. v.1.

LINS, V. Nicolás Guillén: as Elegias antilhanas e a poesia em dilaceramento. Revista Estudos de Literatura Brasileira Contemporânea, Brasília, n.29, jan. 2011. Disponível em: <http://www.red.unb.br/index.php/estudos/article/view/2081/1648>. Acesso em: 4 jul. 2011.

MULLEN, E. The Emergence of Afro-Hispanic Poetry: Some Notes on Canon Formation. Hispanic Review, v.56, n.4, p.435-53, Autumn, 1988.

REVISTA ACADÊMICA. Rio de Janeiro, 1933 (n.1-3); 1934 (n.4-9); 1935 (n.10$15)$; 1936 (n.16-23); 1936/1937 (n.24/25); 1937 (n.26-32); 1938 (n.33-41); 1939 (n.42-47); 1940 (n.48-52); 1941 (n.53-58); 1942 (n.59-62); 1943 (n.63); 1944 (n.64); 1945 (n.65-66).

RIAUDEL, M. Walt Whitman et le Brésil. Paris (texto inédito cedido pelo autor).

SCHWARZ, R. Um mestre na periferia do capitalismo: Machado de Assis. São Paulo: Duas Cidades, 1990.

RUFINONI, S. R. Visionarismo satânico no poema em prosa de Cruz e Sousa: trabalho poético e marginalidade. Teresa: Revista de Literatura Brasileira, São Paulo, n.1, p.175$82,2000$.

TERESA. Revista de Literatura Brasileira. São Paulo, n.3, p.64-5, 2002.

VIANNA, H. Equilíbrio de antagonismos. Folha de S.Paulo. São Paulo, Mais! Supl. 12 mar 2000, p.21.

WEBER, M. A ética protestante e o Espirito do capitalismo. São Paulo: Pioneira; Thomson Learning, 2001. 
RESUMO - O presente ensaio se propõe a examinar o contexto de publicação dos Poemas negros (1947) de Jorge de Lima, buscando, primeiramente, historiar a formação e a consolidação do cânone da poesia afro-americana para, em seguida, rastrear sua repercussão no cenário literário brasileiro dos anos 1930 e 1940, em particular, na Revista Acadêmica, responsável pela edição do livro de Jorge de Lima. Por fim, o ensaio examina os Poemas negros à luz dessa repercussão, considerando os limites ou as contradições ideológicas de seu projeto poético.

PALAVRAS-Chave: Jorge de Lima, Poemas negros, Poesia afro-americana, Revista Acadêmica.

ABSTRACT - The purpose of this essay is to examine the context of Jorge de Lima`s Poemas Negros (1947) publication, by firstly analyzing the formation and consolidation of the canon of African American poetry and then tracking their impact on Brazilian literary scene along the years 1930 and 1940, in particular at Revista Acadêmica, which is responsible for publishing of Jorge de Lima`s book. Finally, this essay studies the inclusion of Poemas Negros in this debate by examining the boundaries or the ideological contradictions of his poetic project.

KEYWORDS: Jorge de Lima, Poemas negros, African American poetry, Revista Acadêmica.

Vagner Camilo é professor do Departamento de Letras Clássicas e Vernáculas da Faculdade de Filosofia Letras e Ciências Humanas da Universidade de São Paulo. É autor de Drummond: da Rosa do Povo à rosa das trevas (Ateliê/Anpoll) e Risos entre pares: poesia e humor românticos (Edusp). @-vcamilo@usp.br

Recebido em 14.8.2012 e aceito em 16.9.2012. 